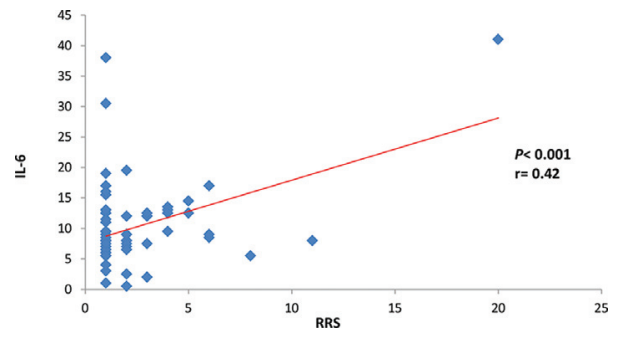

Figure 1. Correlation of RRS with IL-6

Disclosure of Interests: None declared

DOI: 10.1136/annrheumdis-2019-eular.2290

\section{AB0252 RACIAL DISPARITIES IN OUTCOMES FOR PATIENTS WITH RHEUMATOID ARTHRITIS UNDERGOING TOTAL KNEE OR TOTAL HIP ARTHROPLASTY}

Julianna Hirsch ${ }^{1}$, Bella Mehta ${ }^{2}$, Jackie Finik ${ }^{3}$, Serene Mirza ${ }^{2}$, Mark Figgie ${ }^{4}$, Collin Brantner ${ }^{2}$, Iris Navarro-Millan ${ }^{2}$, Susan Goodman ${ }^{2} .{ }^{1}$ Mount Sinai St. Luke'sWest, New York, United States of America; ${ }^{2}$ Hospital for Special Surgery, Weill Cornell Medicine, Rheumatology, New York, United States of America; ${ }^{3}$ Hospital for Special Surgery, Main Campus, Biostatistics, New York, United States of America; ${ }^{4}$ Hospital for Special Surgery, Main Campus, Orthopedics, New York, United States of America

Background: Race is linked to delays in healthcare. Black and Hispanic patients with osteoarthritis have worse pain and function than Whites before arthroplasty. Whether Black and Hispanic patients with RA similarly delay care is unknown.

Objectives: To assess whether Black and/or Hispanic (minority) RA patients have worse pain, function and disease activity at the time of arthroplasty.

Methods: We used prospectively acquired data on RA patients between 10/2013 and 11/2018 prior to total knee arthroplasty (TKA) or total hip arthroplasty (THA). Pain, function, and disease activity were assessed using the visual analogue scale (VAS), the Multidimensional Health Assessment Questionnaire (MD HAQ), and the Disease Activity Score (DAS28). Race, ethnicity, education, income, insurance and medications were collected via self-report questionnaire. Multivariable linear and logistic models examined whether minority status predicted pain, function and disease activity.

Results: $37(23 \%)$ of the 164 patients were minorities (Table 1). MD $\mathrm{HAQ}$ and DAS28 were worse in minorities, only VAS was significant $(p-$ value $=0.029$ ). There was no significant difference in education. Unadjusted comparisons indicated no difference in pain, function, disease activity or medication use between groups. Insurance varied significantly between groups $(p=<0.0001)$. In the multivariable analyses (Table 2 ) minority status was not significantly associated with worse function (MD

Table 1. Cohort

\begin{tabular}{|c|c|c|c|c|}
\hline & $\begin{array}{r}\text { Overall } \\
(\mathrm{N}=164)\end{array}$ & $\begin{array}{c}\text { Minority }^{*} \\
(\mathrm{~N}=37)\end{array}$ & $\begin{array}{c}\text { Non-minority } \\
(\mathrm{N}=127)\end{array}$ & $\mathrm{p}$-value \\
\hline Age, years, median [IQR] & $\begin{array}{l}62.5[54.7 \\
71.2]\end{array}$ & $\begin{array}{l}56.8[51.0 \\
68.8]\end{array}$ & $\begin{array}{c}64.0[55.1 \\
71.5]\end{array}$ & 0.063 \\
\hline $\begin{array}{l}\text { VAS Pain Score, median } \\
{[I Q R]}\end{array}$ & $6.0[4.0,8.0]$ & $7.5[4.0,8.0]$ & $6.0[4.0,8.0]$ & 0.029 \\
\hline $\mathrm{MD}$ HAQ Score, mean \pm SD & $11.8 \pm 5.3$ & $12.3 \pm 5.1$ & $11.6 \pm 5.3$ & 0.528 \\
\hline \multicolumn{5}{|l|}{ Sex } \\
\hline Males & $22(13.41 \%)$ & $3(8.11 \%)$ & $19(15.08 \%)$ & 0.412 \\
\hline \multicolumn{5}{|l|}{ Education } \\
\hline Graduated HS & $18(11.76 \%)$ & $4(12.90 \%)$ & $14(11.48 \%)$ & \multirow[t]{2}{*}{0.762} \\
\hline $\begin{array}{l}\text { Some college or above } \\
\text { Insurance }\end{array}$ & $135(88.24 \%)$ & $27(87.10 \%)$ & $108(88.52 \%)$ & \\
\hline Commercial & $54(33.13 \%)$ & $9(29.03 \%)$ & 45 (41.28\%) & \multirow[t]{4}{*}{$<0.001$} \\
\hline Medicare & $77(47.24 \%)$ & $13(41.94 \%)$ & $64(58.72 \%)$ & \\
\hline Medicaid & $9(5.52 \%)$ & $9(29.03 \%)$ & $0(0.0 \%)$ & \\
\hline $\mathrm{N} / \mathrm{A}$ & $23(14.11 \%)$ & $6(16.22 \%)$ & $17(13.49 \%)$ & \\
\hline \multicolumn{5}{|l|}{ Biologics } \\
\hline Yes & 90 (55.56\%) & $23(62.16 \%)$ & 67 (53.60\%) & 0.452 \\
\hline
\end{tabular}

*Minority status: Black or African American, Hispanic or Mixed.

IQR: Interquartile Range

VAS: Visual Analogue Scale

MD HAQ: Multidimensional Health Assessment Questionnaire

DAS28: Disease Activity Score28

HS: High School
Table 2. Multivariable analysis to determine the risk of DAS28, VAS Pain Score, and MD HAQ Score (Generalized Logistic Model)

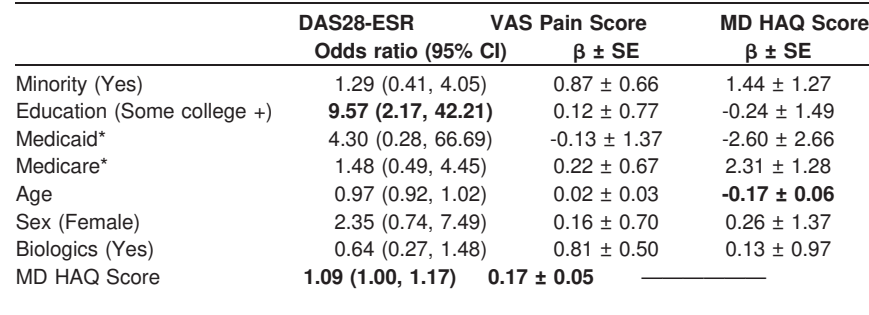

${ }^{*}$ Ref: Commercial

Significant variables in bold

HAQ) $[p=0.26]$, disease activity (DAS28-ESR) $[p=0.658]$, or VAS pain $[p=0.18]$. Increased age was significantly associated with better function $(p=0.004)$.

Conclusion: For Black and/or Hispanics with RA undergoing THA or TKA at a high-volume specialty hospital, minority status was not significantly associated with pain, disability or RA disease activity at the time of elective arthroplasty.

Disclosure of Interests: Julianna Hirsch: None declared, Bella Mehta: None declared, Jackie Finik: None declared, Serene Mirza: None declared, Mark Figgie: None declared, Collin Brantner: None declared, Iris Navarro-Millan: None declared, Susan Goodman Grant/research support from: Novartis: research support, Consultant for: Novartis, UCB, Pfizer: consulting

DOI: 10.1136/annrheumdis-2019-eular.4997

\section{\begin{tabular}{l|l} 
AB0253 & BIOMARKERS OF CLINICAL RESPONSE TO IL6-R
\end{tabular} BLOCKADE IN DMARDS INCOMPLETE RESPONDERS (AR-BIOM TRIAL): IL23 AND BAFF AS BIOLOGICAL TARGETS, AND ALBUMIN AS BIOLOGICAL PREDICTOR}

Gianfranco Ferraccioli ${ }^{1}$, Barbara Tolusso ${ }^{2}$, Florenzo lannone ${ }^{3}$, Maurizio Rossini ${ }^{4}$, Piercarlo Sarzi-Puttini ${ }^{5}$, Marcello Govoni ${ }^{6}$, Rosario Foti ${ }^{7}$, Andrea Doria ${ }^{8}$, Francesco Paolo Cantatore ${ }^{9}$, Giovanni Francesco Miceli ${ }^{10}$, Oscar Massimiliano Epis ${ }^{11}$, Anna Laura Fedele ${ }^{2}$, Antonio Carletto ${ }^{4}$, Nicola Maruotti ${ }^{9}$, Elena De Stefani ${ }^{6}$, Giorgio Amato ${ }^{7}$, Elisa Gremese ${ }^{12}$, Giovanni Lapadula ${ }^{3}$, GISEA (Gruppo Italiano Studio Early Arthritis). ${ }^{1}$ Università Cattolica del Sacro Cuore, Division of Rheumatology, Rome, Italy; ${ }^{2}$ Fondazione Policlinico Universitario A. Gemelli IRCCS, Division of Rheumatology, Rome, Italy; ${ }^{3}$ University of Bari, Bari, Italy; ${ }^{4}$ University of Verona, Verona, Italy; ${ }^{5}$ L. Sacco University Hospital, Milan, Italy; ${ }^{6}$ University of Ferrara, Ferrara, Italy, ${ }^{7}$ Policlinico di Catania, Catania, Italy;

${ }^{8}$ University of Padova, Padua, Italy, ${ }^{9}$ University of Foggia, Foggia, Italy;

${ }^{10}$ Policlinico G. Martino, Messina, Italy; ${ }^{11}$ Grande Ospedale Metropolitano Niguarda, Milan, Italy; ${ }^{12}$ Fondazione Policlinico Universitario A. Gemelli IRCCS Università Cattolica del Sacro Cuore, Division of Rheumatology, Rome, Italy

Background: The therapeutic algorithm in persistently active Rheumatoid Arthritis, despite conventional synthetic DMARDs(csDMARDs), identifies TNF $\alpha$ blockers and other biologics as first line treatment, without clear indications of which biologic should be adopted first in persistently active patients.

Objectives: In the AR-BIOM trial we analyzed several biomarkers to define which one could help to identify the best responder to IL6-R blockade.

Methods: Sixty-nine RA persistently active despite csDMARDs treatment, were enrolled in this Interventional Phase IV, prospective, multicenter non-randomized, no-profit study(Clinical Trial:n.2012-001760-30) and followed for 18 months after Tocilizumab(TCZ) treatment monotherapy or in combination with csDMARDs. The study was conducted in 10 outpatient clinics of "Gruppo Italiano di Studio sulle Early Arthritis" network(GISEA Study Group) in Italy. The primary end point was the clinical response to $\mathrm{TCZ}$, as $\operatorname{LDA}(\mathrm{DAS}<2.4)$ at 12 months follow-up(FU), correlated with Matrix 1 (pathway of Innate inflammation:IL-8,MCP1,Chemerin) vs Matrix 2(Pathway of IL1/IL6/TH17:IL1 $\alpha, I L 1 \beta, I L 17, I L 23)$ along with the Pathway of regulatory $T$ cells activity(IL-10,BAFF) and acute phase reactants (Albumin, Fibrinogen,CRP,ESR) as biomarkers of interest. DAS and SDAI remission were secondary end-points at 12 and 18 months FU. A ROC analysis of soluble biomarkers was performed to obtain thresholds allowing the prediction of DAS-remission or LDA at 12 months FU. A multivariate logistic analysis, in which "LDA or DAS/SDAI remission at 12 months FU" were the dependent variables, was performed.

Results: During the 18 months of the study, 9/69 patients(13.0\%) discontinued the study because of treatment failure, 2(2.9\%) for an $A E, 2$ for a SAE, and $5(7.2 \%)$ for other reasons. At 12 months FU, LDA was achieved in $75.0 \%$ and DAS-R and SDAI-R in $63.3 \%$ and $41.7 \%$ 
respectively, of RA patients, without significant differences between mono and combination therapy. Considering baseline biomarkers predictive of LDA at 12 months FU, IL23 plasma levels $\geq 43.6 \mathrm{pg} / \mathrm{ml}$ arose as potent predictor [OR(95\%Cls):20.0(1.9-211.2)], whereas the best predictors of DAS-R were baseline BAFF plasma levels $\geq 563.3 \mathrm{pg} / \mathrm{ml}$ [OR(95\%Cls):3.9 (1.1-14.3)] and IL23 plasma levels $\geq 43.6 \mathrm{pg} / \mathrm{ml}$ [OR(95\%Cls):4.1(1.1-15.2)]. In addition, Albumin levels $\geq 4.25 \mathrm{~g} / \mathrm{dl}$ at 3 months $\mathrm{FU}$, arose as a biochemical parameter predicting DAS-R [OR(95\%Cls):26.0(3.9-173.1)] and SDAI-R [OR(95\%Cls):5.3(1.2-22.9)] at 12 months FU.

Conclusion: IL23 and BAFF related inflammation are targets of IL6 blockade that significantly increases Albumin levels. High plasma levels of IL23 and BAFF at baseline represent biomarkers for LDA and DAS-R achievement in RA inflammation driven by IL6. Albumin after three months of therapy represents the strongest predictor of remission at 12 months.

Disclosure of Interests: Gianfranco Ferraccioli Speakers bureau: BMS, Roche, Barbara Tolusso: None declared, Florenzo lannone Consultant for: $F$ lannone has received consultancy fees and/or speaker honoraria from Pfizer, AbbVie, MSD, BMS, Novartis, Lilly, UCB outside this work, Speakers bureau: $F$ lannone has received consultancy fees and/or speaker honoraria from Pfizer, AbbVie, MSD, BMS, Novartis, Lilly, UCB outside this work, Maurizio Rossini: None declared, Piercarlo Sarzi-Puttini Speakers bureau: Novartis, Marcello Govoni Paid instructor for: Pfizer, Roche, Speakers bureau: Pfizer, Abbvie, MSD, Roche, Eli-Lilly, Celgene, Sanofi, Janssen, Rosario Foti: None declared, Andrea Doria: None declared, Francesco Paolo Cantatore Speakers bureau: PFIZER, ROCHE, Giovanni Francesco Miceli: None declared, oscar massimiliano epis: None declared, Anna Laura Fedele: None declared, Antonio Carletto: None declared, Nicola Maruotti: None declared, Elena De Stefani: None declared, Giorgio Amato: None declared, Elisa Gremese Consultant for: AbbVie, BMS, Celgene, Janssen, Lilly, MSD, Novartis, Sanofi, UCB, Roche, and Pfizer, Speakers bureau: BMS, Speakers bureau: Roche, Speakers bureau: AbbVie, BMS, Celgene, Janssen, Lilly, MSD, Novartis, Sanofi, UCB, Roche, and Pfizer, Giovanni Lapadula: None declared

DOI: 10.1136/annrheumdis-2019-eular.5822

\section{AB0254 NEUTROPHIL-LYMPHOCYTE RATIO AND PLATELET- LYMPHOCYTE RATIO IN PATIENTSRECEIVING ANTIRHEUMATIC THERAPY: RELATIONSHIP TO CLINICAL AND LABORATORY MARKERS OF DISEASE ACTIVITY}

Iris Paola Guzmán-Guzmán ${ }^{1}$, Oscar Zaragoza-García ${ }^{1}$, José Eduardo NavarroZarza ${ }^{2}$, Isela Parra-Rojas ${ }^{1}{ }^{1}$ Universidad Autónoma de Guerrero, Facultad de Ciencias Químico Biológicas, Chilpancingo, Guerrero, Mexico; ${ }^{2}$ Hospital General de Chilpancingo, Departamento de Reumatología y Medicina Interna., Chilpancingo, Guerrero, Mexico

Background: The use of antirheumatic drugs is key to limit or prevent inflammation and joint damage in rheumatoid arthritis (RA). Recently, neutrophil-lymphocyte ratio (NLR) and platelet-lymphocyte ratio (PLR) has been considered markers of clinical activity in $\mathrm{RA}^{1}$, however its relationship with serological and clinical parameters in patients receiving disease modifying drugs (DMARDs) therapy has been poorly evaluated.

Objectives: To analyze the association of NLR and PLR with serological and clinical parameters related to the clinical prognosis in RA patients with antirheumatic treatment.

Methods: A cross-sectional study was carried out in 150 women with RA (mean age of 45.5 years, and mean duration of disease of 8 years) all diagnosed according to ACR/EULAR 2010 criteria and receiving DMARDs and corticosteroids (Cs) therapy. The clinical features and DAS-28 score were analyzed by a rheumatologist professional. The NLR and PLR, as well as the erythrocyte sedimentation rate (ESR), high sensitivity $C$ reactive protein (hsCRP) levels, rheumatoid factor (RF) and anti-cyclic citrullinated peptides (anti-CCPs) antibodies, were determined in the laboratory. Results: The medical schemes prescribed commonly were: Methotrexate (MTX) monotherapy and MTX combination with chloroquine, sulfasalazine, leflunomide and Cs. The NLR was correlated with DAS28-ESR and DAS28-hsCRP scores. The values of NLR $>2.2$ (percent neutrophil/percent lymphocyte) were associated with hsCRP $>12 \mathrm{mg} / \mathrm{L}(\mathrm{OR}=2.45, \mathrm{p}=0.036)$, DAS28-hsCRP $>5.1 \quad(\mathrm{OR}=2.69, \mathrm{p}=0.07)$ and with anti-CCPs-positive $(>5 \mathrm{U} /$ $\mathrm{mL})(\mathrm{OR}=1.57, \mathrm{p}=0.41)$. While, PLR $>10.4$ (platelet count $\times 10^{3} / \mathrm{mm}^{3} /$ percent lymphocyte) was too associated ( $O R=3.72, \quad p=0.004 ; O R=2.51, \quad p=0.08$; $\mathrm{OR}=2.96, \mathrm{p}=0.07$, respectively). Serological autoantibodies, when was considered in combination, the anti-CCPs/RF-positive patients showed a higher correlation between NLR and PLR with the parameters of clinical activity [tender joints count $(r=0.19, p=0.036 ; r=0.16, p=0.07)$, swollen joints count $(r=0.15, p=0.08 ; \quad r=0.14, p=0.11)$ and DAS28-hsCRP score $(r=0.16, p=0.06 ; r=0.17, p=0.05)]$, however this correlation was higher in anti-CCPs-positive but RF-negative patients. In addition, was observed that patients with DMARDs combination and a greater number of drugs had increased NLR and PLR.

Conclusion: NLR and PLR could be considered markers for the evaluation of the clinical course and response to therapy DMARDs in RA patients.

\section{REFERENCE}

[1] Sargin G, Senturk T, Yavasoglu I, et al. Relationship between neutrophillymphocyte, platelet-lymphocyte ratio and disease activity in rheumatoid arthritis treated with rituximab. Int J Rheum Dis. 2018. doi.org/10.1111/ 1756-185X.13400

Disclosure of Interests: None declared

DOI: 10.1136/annrheumdis-2019-eular.7762

\section{AB0255 CLINICO- BIOLOGICALPROFILE OF RHEUMATOID ARTHRITIS WITH PERIODONTITIS AND PORPHYROMONAS GINGIVALIS}

Farida Mechid ${ }^{1}$, Houda Hafirassou ${ }^{1}$ Malika Meddad ${ }^{2}$, Samir Salah $^{3}$, Saida Merad $^{4}$ Nawel Blidi ${ }^{1}$,Chafia Makhloufi-Dahou ${ }^{1}, .{ }^{1}$ Rheumatology, Mohamed Lamine Debaghine hospital, ALGIERS, Algeria; ${ }^{2}$ Periodontology, Mustapha Bacha Hospital, ALGIERS, Algeria; ${ }^{3}$ Immunology. Dely brahim, institut Pasteur, ALGIERS, Algeria; ${ }^{4}$ Bacteriology. Dely brahim, institut Pasteur, Algiers, Algeria, ALGIERS, Algeria

Background: The Periodontitis (PD) is currently recognized as a risk factor of occurrence of the rheumatoid arthritis(RA). The porphyromonas gingivalis ( $P$.gin givalis) figure among the main germs incriminated in the occurrence of the PD. Previous studies have shown that antibodies to $P$. gingivalis are associated with anti-CCP antibody in patients with RA. However others studies have not demonstrated this association.

Objectives: The aim of this study was to seek for a possible association between clinico-biological parameters of the RA and the presence of the P.gingivalis.

Methods: We conducted a prospective study of 69 patients with early rheumatoid arthritis ( $\leq 2$ years), naive of biotherapy. Smokers, diabetics, and subjects who received dental care and those who used antibiotics in the previous 6 months were not included. Periodontal status, demographic, clinical activity, and anticyclic citrullinated peptide antibodies (anti-CCP) parameters were determined. The P. gingivalis has been searched in patients with a PD. We sought to investigate an association between Rheumatoid disease activity (DAS28), anticyclic citrullinated peptide antibodies (anti-CCP) and P.gingivalis.

Results: The mean age of our patients was $40.75 \pm 12.04$, the mean duration of the illness was $14.30 \pm 6.76$ months (extremes: 1-24 months). ACPA was detected in $88 \%$ of patients and the mean titre was $255.57 \pm 409.78$.

$43 \%$ of patients have presented a PD. The P.gingivalis has been detected in $59 \%$ of PD. The means DAS28 of patient with and without P.gingivalis is respectively $4.40 \pm 1.32$ and $4.15 \pm 1.45$, and there was no significant difference $(p=0.65)$. There was also no association observed between anti CCP and the presence of P.gingivalis(the mean titre of anti CCP was $249.47 \pm 294.58$ with P.gingivalis and 258.67 \pm 93.48 without $P$.gingivalis, $p=0.74$ ).

Conclusion: This study showed that periodontitis is frequent in rheumatoid arthritis. More than half of our patients suffering of periodontitis were infected by porphyromonas gingivalis. Rheumatoid disease activity does not seem to be related to porphyromonas gingivalis. In addition therewas no association between antiCCP antibody and the presence of porphyromonas gingivalis.

\section{REFERENCES}

[1] Johansson L, Sherina N, Kharlamova N, Potempa B, Larsson B, Israelsson L, Potempa J, Rantapää-Dahlqvist S, Lundberg K. Concentration of antibodies against Porphyromonas gingivalis is increased before the onset of symptoms of rheumatoid arthritis. Arthritis Research 18: 201

[2] Bello-Gualtero JM, Lafaurie GI, Hoyos LX et al. Periodontal Disease in Individuals With a Genetic Risk of Developing Arthritis and EarlyRheumatoid Arthritis: A Cross-Sectional Study. J Periodontol. 2016;87(4):346-56.

[3] Fisher BA, Cartwright AJ, Quirke AM, de Pablo P, Romaguera D, Panico $S$ et al. Smoking, Porphyromonas gingivalis and the immune response to citrullinated autoantigens before the clinical onset of rheumatoid arthritis in a Southern European nested case-control study. BMC Musculoskelet Disord. 2015;16:331

[4] Cheng Z, Meade J, Mankia K, Emery P, Devine DA. Periodontal disease and periodontal bacteria as triggers for rheumatoid arthritis. Best Pract Res Clin Rheumatol. 2017;31(1):19-30.

Disclosure of Interests: None declared

DOI: 10.1136/annrheumdis-2019-eular.3342 